\title{
Striving for Success in Outgroup Settings: Effects of Contextually Emphasizing Ingroup Dimensions on Stigmatized Group Members' Social Identity and Performance Styles
}

\author{
Belle Derks \\ Colette van Laar \\ Naomi Ellemers \\ Leiden University, the Netherlands
}

\begin{abstract}
For members of stigmatized groups, being confronted with highstatus outgroup members threatens social identity and undermines performance on status-relevant dimensions. Two experiments examined whether the negative effects of outgroup contexts are alleviated when value is expressed for a dimension on which the stigmatized ingroup excels. Specifically, the authors assessed whether ingroup versus outgroup context and contextual value for ingroup dimensions affects group members' reactions to failure on status-relevant dimensions and subsequent performance. Experiment 1 showed that in comparison to ingroup contexts, outgroup contexts induce stigmatized group members to protect social identity and to feel more agitated following negative performance feedback. Experiment 2 showed that when others in the context emphasize the importance of a dimension on which the ingroup excels, the negative effects of outgroup contexts are alleviated, stigmatized group members feel more cheerful concerning an upcoming task, and task performance is characterized by a focus on success.
\end{abstract}

Keywords: group context; integration; stigma; social identity threat; focus on success vs. failure

$\mathbf{W}$ hen individuals who belong to stigmatized groups are confronted with a high-status outgroup, this threatens their social identity (Tajfel \& Turner, 1986). A context dominated by high-status outgroup members enhances the salience of performance dimensions on which the high-status group excels, such as academic performance or economic success, emphasizing the relative inferiority of stigmatized group members on these dimensions. This article examines the effects of group context (ingroup vs. outgroup) on low-status group members' social identity protection and their focus on success versus failure. In two experiments, we examine whether the negative effects of outgroup contexts on stigmatized group members' well-being and motivated performance can be alleviated. We hypothesize that protecting the social identity of stigmatized group members by contextually valuing dimensions on which their ingroup excels increases well-being and induces a focus on success, even in relatively threatening outgroup contexts.

\section{How Does Group Context Affect Social Identity?}

The first objective of this research is to examine how exactly group context affects stigmatized group members' well-being and social identity protection. According to Inzlicht and Ben-Zeev (2000), intergroup settings constitute "threatening environments" in which stigmatized group members are more aware of their devalued identity. This can result in performance deficits. For instance, women confronted with men when taking a diffi-

Authors' Note: This research was supported by a grant from the Dutch National Science Foundation (NWO) (Grant 261-98-906) as part of the Social Cohesion Program. We thank Manuela Barreto, Kai Sassenberg, Daan Scheepers, Katherine Stroebe, and two anonymous reviewers for their helpful comments on earlier drafts of this article, and Wies Kerkvliet for her assistance with data collection. Correspondence concerning this article should be addressed to Belle Derks, Leiden University, Department of Social and Organizational Psychology, P.O. Box 9555, 2300 RB Leiden, the Netherlands; e-mail: Derks@fsw .leidenuniv.nl.

PSPB, Vol. 32 No. 5, May 2006 576-588

DOI: $10.1177 / 0146167205283336$

(c) 2006 by the Society for Personality and Social Psychology, Inc. 
cult math test show lower performance than women who take the math test in the presence of other women (Inzlicht \& Ben-Zeev, 2000; Sekaquaptewa \& Thompson, 2003). This is consistent with predictions from selfcategorization theory (Turner, Hogg, Oakes, Reicher, \& Wetherell, 1987), which posits that intergroup settings increase the contextual salience of group membership and of the relative standing of one's group (see also McGuire \& Padawer Singer, 1976). As a result, for stigmatized group members, the need to protect social identity is higher in outgroup settings than in ingroup settings. Accordingly, research on the effects of solo status indicates that being a minority in a context consisting of outgroup members is especially damaging for members of stigmatized groups (Swan \& Wyer, 1997).

We hypothesize that these so-called outgroup contexts are threatening to social identity because they are perceived to emphasize the importance of statusdefining dimensions on which stigmatized groups underperform compared to high-status groups. For example, we expect that women in a mathematics class dominated by men will perceive the men within that context to attach high value to math. However, when women take mathematics in a class with mostly women, we expect them to perceive others in that context to place less emphasis on the importance of mathematics because it is not a dimension that characterizes the female gender group. Thus, we expect that high contextual value attached to status-defining outgroup dimensions increases social identity threat in outgroup contexts.

Because this implies that an outgroup context increases experienced social identity threat, it is also expected to increase the use of social identity protecting strategies. One well-documented way to cope with social identity threat is to devalue the dimensions on which the stigmatized ingroup is outperformed by high-status outgroups (Crocker \& Major, 1989; Schmader \& Major, 1999). Of importance, the use of domain devaluation is not without social costs. Although devaluing statusdefining dimensions may protect social identity, this devaluation can also lower motivation and performance on status-defining dimensions. When this occurs, the low expectations that exist about the ingroup on statusdefining dimensions become a self-fulfilling prophecy that perpetuates the ingroup's low status. A possibly less damaging strategy to counter social identity threat is to attach value to alternative dimensions on which the ingroup is superior to the high-status outgroup (Crocker \& Major, 1989). For instance, women who experience social identity threat when interacting with men can protect their social identity by comparing themselves with men on a dimension such as social skills. Because intergroup comparisons on such alternative dimensions reflect positively on the ingroup, social identity is protected.

The first objective of this article is to examine more closely the psychological process underlying social identity threat in outgroup settings by examining whether increased threat results from perceiving high contextual value of the outgroup dimension.

\section{How Can the Effects of Outgroup Contexts Be Alleviated?}

A second objective of this research is to examine whether it is possible to alleviate the negative effects of outgroup contexts on a group level. In parallel to selfaffirmation theory (Steele, 1988), which describes how individuals can deflect threat to personal identity by focusing on those dimensions on which they excel, we propose that social identity threat in outgroup contexts can be alleviated by emphasizing dimensions on which the stigmatized group excels. However, in the current research, we diverge from self-affirmation theory not only by examining this as a group process but also by investigating whether such self-enhancement, in addition to alleviating identity threat, actually benefits performance on outgroup dimensions; that is, whereas self-affirmation theory addresses the benefits of selfaffirmation for well-being, we predict that enhancing social identity by emphasizing dimensions of ingroup success also affects motivated performance. Moreover, examining the effects of group dimensions on the self helps to understand group-level responses to disadvantage (e.g., work for higher group status) in addition to more individual-level coping strategies (e.g., individual mobility; Wright, 2001); that is, when affirmation of the group value enhances social identity, group members can preserve motivation on outgroup dimensions without having to disidentify from their group. In the current research, we will test whether contextually emphasizing alternative dimensions can alleviate the negative effects of outgroup contexts on stigmatized group members' well-being, social identity, and performance.

From this point on, we take the perspective of the stigmatized group and refer to status-defining dimensions as outgroup dimensions (dimensions on which the outgroup claims superiority) and to alternative dimensions as ingroup dimensions (dimensions that positively characterize the stigmatized ingroup).

\section{Affective Reactions to \\ Failure and Task Performance Styles}

In addition to examining low-status group members' well-being and social identity protection, we address variables that affect future persistence and performance on outgroup dimensions. For stigmatized group members to become motivated to increase their performance on 
the outgroup dimension, it is important that previous personal or group failure on this dimension does not deter them from persisting in the future. Different social psychological models point to the fact that individuals can appraise achievement situations in terms of challenge (success is a possible outcome) or as a threat (failure has to be averted). For instance, the trichotomous model of achievement goals (Elliot \& Church, 1997) proposes a division between performance-approach goals that focus individuals on approaching competence and performance-avoidance goals that focus individuals on avoiding incompetence. Similarly, regulatory focus theory (Higgins, 1997) states that individuals can frame achievement goals in terms of loss versus nonloss and as gain versus nongain. Individuals who are promotion focused interpret achievement situations in terms of success and nonsuccess and eagerly strive to perform well. Individuals with a prevention focus interpret achievement situations in terms of failure versus nonfailure, which elicits vigilant behavior to avoid failure.

Whether stigmatized group members view achievement situations as settings in which to vigilantly avoid failure or as settings in which to eagerly approach success has important consequences for their chances to improve performance on outgroup dimensions. Stigmatized group members who focus on failure versus nonfailure will try to avoid situations in which they run the risk of failing. This is the case when they have to perform on the outgroup dimension (on which they or their group has failed in the past). However, previous failure will not deter stigmatized group members who focus on success because they will interpret the situation as a challenge to achieve success on the outgroup dimension. Thus, contextual factors that increase stigmatized group members' focus on success can increase persistence on outgroup dimensions and ultimately result in superior performance.

In this research, we examine whether different intergroup contexts influence the affective reactions of stigmatized group members to failure on outgroup dimensions and the task performance strategy that they adopt in subsequent performance on these dimensions. Consistent with other work examining performance styles or focus, we examine how focus shifts in reaction to situational cues. For instance, Seibt and Förster (2004) show that whereas positive stereotypes lead group members to focus on positive outcomes, and induce a promotion focus on success, negative stereotypes lead group members to focus on negative outcomes, inducing a prevention focus on failure. We borrow ideas from regulatory focus theory in examining shifts in different types of failure emotions as a consequence of experimental context. According to regulatory focus theory, individuals who are focused on success feel cheerful after success but de- jected after failure. However, individuals who are focused on failure feel agitated after failure and relaxed after success (Higgins, Shah, \& Friedman, 1997). In addition to these shifts in affective consequences of failure, we examine whether group context and emphasis on ingroup or outgroup dimensions determine the type of performance style individuals use. Therefore, we examine whether, after experiencing failure, stigmatized group members invest time toward minimizing failure or toward maximizing success. We hypothesize that stigmatized group members are more focused on failure in outgroup contexts than in ingroup contexts. This is because we expect that in outgroup contexts, outgroup members are perceived to attach high value to the outgroup dimension, emphasizing the ingroup's failure on this dimension. Ingroup contexts, however, should be perceived to attach high value to the ingroup dimension, increasing the focus on the ingroup's success on this dimension. Similarly, we hypothesize that contextually emphasizing the ingroup dimension can alleviate the negative effects of outgroup contexts by increasing the focus on success.

\section{The Present Research}

In two experiments, we examine how group context affects stigmatized group members' social identity protection, affective reactions to failure, and subsequent task performance styles. Moreover, we test whether the negative effects of outgroup contexts are alleviated when the context also values an ingroup dimension. In both experiments, we studied women within a job application context, which represents a setting in which women in the Netherlands are stigmatized. Experiment 1 concentrates on social identity protection and measures emotions that are typical of a focus on success versus nonsuccess (i.e., cheerful/dejected) or on failure versus nonfailure (i.e., relaxed/agitated). This experiment systematically tests the psychological process we propose to mediate the occurrence of social identity threat and focus on failure in outgroup contexts: We test whether others present in outgroup contexts are indeed perceived to value outgroup dimensions highly and whether this high contextual value of the outgroup dimension causes increased social identity protection and a focus on failure. To extend the affective indicators of focus on success versus failure, Experiment 2 also includes behavioral indicators of focus on success versus failure in terms of the time low-status group members spend on a task focusing on decreasing failure versus increasing success.

\section{EXPERIMENT 1}

Experiment 1 examined how group context (ingroup vs. outgroup) and value attached to the ingroup or the outgroup dimension influences the perceived contex- 
tual emphasis on the ingroup and the outgroup dimension, the attitude toward an upcoming achievement situation involving the outgroup dimension, social identity protection, and emotions indicating a focus on success versus nonfailure. Furthermore, we examined whether the negative effects of outgroup contexts are explained by the high value others in the context are perceived to attach to the outgroup dimension.

\section{Hypotheses}

We hypothesized that compared to ingroup contexts, outgroup contexts increase social identity threat (Hypothesis 1a: main effect of group context). This would be evident from a higher perceived contextual value of the outgroup dimension, a more negative attitude toward an achievement situation involving the outgroup dimension, more social identity protection (either by valuing the ingroup dimension or by devaluing the outgroup dimension), and more emotions typical of a focus on failure (i.e., agitation). At the same time, we expected that emphasizing the ingroup dimension alleviates some of these negative effects (Hypothesis 1b: main effect of contextual emphasis). This would be evident from a higher perceived contextual value of the ingroup dimension, a more positive attitude toward an achievement situation involving the outgroup dimension, less social identity protection (either lower personal value attached to the ingroup dimension or less devaluing of the outgroup dimension), and more emotions typical of a focus on success (i.e., cheerfulness) when the ingroup dimension was contextually emphasized. Finally, we hypothesized that the increased use of social identity protection and the increased emotions typical of focus on failure in the outgroup context are caused by the higher perceived contextual value of the outgroup dimension in the outgroup context (Hypothesis 2: contextual value of the outgroup dimension mediates the main effect of group context on social identity protection and agitation).

\section{METHOD}

\section{Participants}

Participants were 181 female students of the University of Tilburg in the Netherlands. Following a conservative suspicion check, 11 participants were excluded because they spontaneously indicated not believing that there would be an examination on the outgroup dimension. The remaining 170 participants had a mean age of 21 years $(S D=2.04)$.

\section{Procedure}

Participants were seated in separate computer cubicles and received all information via the computer. The study was presented as examining gender differences in performance on two tests that were used in assessment centers. In the Netherlands, applicants are often tested in assessment centers as part of the selection process. Two bogus tests were administered supposedly measuring two cognitive abilities: creative integration and inferential flexibility. These two dimensions were used instead of existing stereotypic male and female dimensions to enable us to manipulate low performance on the outgroup dimension and high performance on the ingroup dimension in all participants. Creative integration was described as the ability to combine ideas and to see connections between concepts that initially seem incompatible. Inferential flexibility was described as the ability to quickly oversee a situation and to pay attention to different aspects at once. The 10-item creative integration test was adapted from McFarlin and Blascovich's Remote Associates Test (1984), in which participants are asked to find a word that is related to three presented words as quickly as possible. On the basis of a pretest, we selected eight difficult and two easy items to ensure that all participants would find low performance credible. To measure inferential flexibility, participants were asked to solve 10 anagrams consisting of six letters as quickly as possible. We selected relatively easy anagrams (based on pretesting) to ensure that participants would feel successful on this test.

Establishing group performance. Participants received preprogrammed feedback about the performance of the ingroup and outgroup. They learned that the ingroup had performed "below average" on the creative integration test (the outgroup dimension) but "above average" on the inferential flexibility test (the ingroup dimension). To prevent group members from deflecting this negative feedback by arguing that their individual performance did not reflect this intergroup difference (Spears, Doosje, \& Ellemers, 1999), we also provided participants with personal performance feedback on these dimensions (which mirrored ingroup performance). In addition, participants were informed that previous research had established that, in general, men perform better than women on creative integration but women, in general, perform better than men on inferential flexibility.

Manipulation of contextual emphasis. Supposedly to measure their ability to concentrate, participants were asked to read, memorize, and answer questions about a fake magazine article that contained the contextual emphasis manipulation. In the control conditions, participants read about the importance of assessments in general. In the other conditions, the article stressed how important either the ingroup or the outgroup dimension was according to employers and that the test mea- 
suring that dimension was often used in assessment centers. We checked this manipulation with three questions for each dimension $\left(\alpha_{\text {ingroup dimension }}=.88, \alpha_{\text {outgroup dimension }}=\right.$ .79; e.g., "How important do employers think it is to test applicants with the creative integration test?").

Manipulation of group context. Next, participants were told that there would be an oral examination on one of the tests, together with three other participants, and that they were randomly assigned to perform the oral examination of the outgroup dimension. Participants were shown the gender of the three other participants and these were either all men or all women. We checked this manipulation with six items $(\alpha=.88$; e.g., "What is the proportion of women and men in the group in which you will perform the oral examination?"). After measuring the dependent variables (see below), to check for suspicion, participants were asked to write for 2 minutes about thoughts that they had had during the experiment. Finally, participants were debriefed, thanked, and paid for their participation.

\section{Measures}

All measures were assessed on 9-point scales. Perceived direct contextual value was assessed with one item for each dimension (e.g., "I think that the other three participants find creative integration an important ability"). We measured attitude toward the oral examination by asking participants how satisfied and happy they were with the group in which they would perform the test and whether they were looking forward to the oral examination $(\alpha=.87)$. Emotions typical of a focus on failure were measured by asking how relaxed (recoded), tense, nervous, and anxious participants felt as a result of the feedback they received $(\alpha=.93)$. Emotions typical of a focus on success were measured by asking how disappointed, discouraged (both recoded), cheerful, and satisfied participants felt as a result of the feedback they received $(\alpha=$ .84). Personal value attached to the ingroup and the outgroup dimension was measured with three questions for each dimension (e.g., "It is important to me to perform well on creative integration"; $\alpha_{\text {ingroup dimension }}=.80$, $\alpha_{\text {outgroup dimension }}=.83$ ).

\section{RESULTS}

\section{Manipulation Checks}

As intended, only contextual emphasis significantly affected the perceived importance of the ingroup and the outgroup dimension. Participants indicated that employers considered the outgroup dimension more important when they had read about the importance of this dimension $(M=7.25, S D=.88)$ than when they had read about the importance of the ingroup dimension $(M=$ $6.55, S D=1.06$ ) or about assessments in general (control

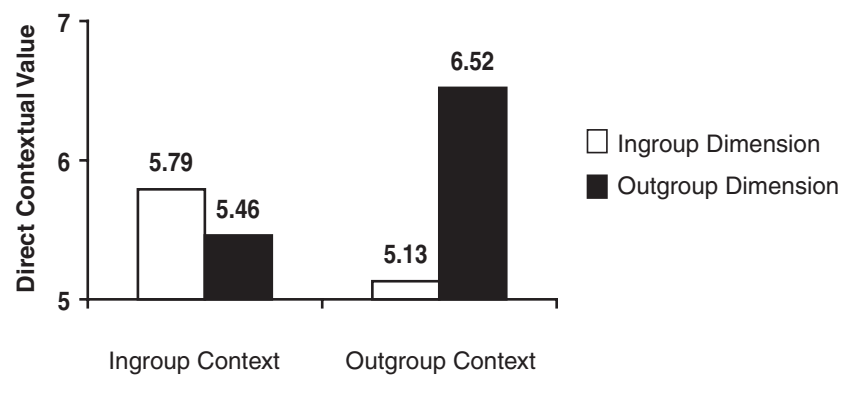

Figure 1 Direct contextual value perceived to be attached to the ingroup dimension and the outgroup dimension in the ingroup and the outgroup context in Experiment 1.

condition, $M=6.62, S D=1.05), F(1,167)=8.63, p<.001$, $\eta^{2}=.10$. Similarly, reading about the contextual importance of the ingroup dimension resulted in higher reported importance to employers of this dimension $(M=7.23, S D=1.18)$ than reading about the importance of the outgroup dimension $(M=6.50, S D=1.17)$ or assessments in general $(M=6.68, S D=1.13), F(1,167)=$ 6.07, $p=.003, \eta^{2}=.07$.

Manipulation checks of group context indicated only one significant main effect: Participants in the ingroup condition indicated that the group in which the oral examination was to be administered consisted of more women $(M=4.24, S D=.90)$ than did participants in the outgroup condition $(M=7.25, S D=.58), F(1,164)=$ 654.41, $p<.001, \eta^{2}=.80$.

\section{Perceived Contextual Value}

A 2 (group context) $\times 3$ (contextual emphasis $) \times 2$ (within-subjects: ingroup/outgroup dimension) MANOVA revealed one significant effect. Consistent with Hypothesis 1a, the perceived contextual value attached to the ingroup and the outgroup dimension interacted with group context, $F(1,164)=50.52, p<.001$, $\mathrm{h}^{2}=.24$. As shown in Figure 1, whereas participants in the outgroup context perceived that other participants valued the outgroup dimension more, $t(82)=6.52, p<.001$, participants in the ingroup context expected others to value the ingroup dimension more, $t(86)=-2.66, p<.01$. In contrast to Hypothesis $1 b$, contextual emphasis on the ingroup or outgroup dimension did not affect the value participants expected other participants to attach to these dimensions, $F(2,164)=1.41, p=.25$.

\section{Attitude Toward the Oral Examination} of the Outgroup Dimension

Consistent with Hypothesis 1a, participants in the outgroup condition reported a more negative attitude toward the oral test of the outgroup dimension $(M=$ 


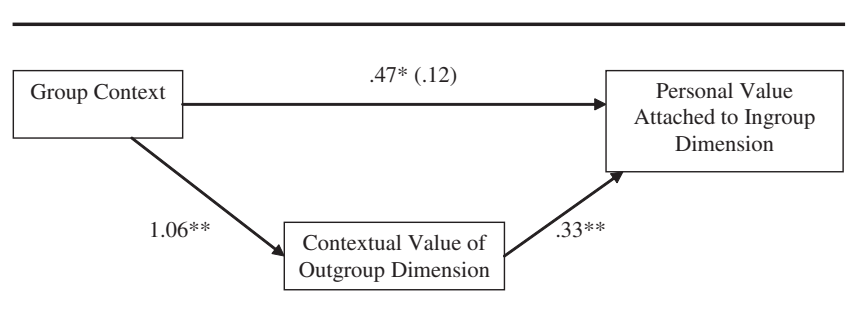

Figure 2 Mediation of the effect of group context on personal value attached to the ingroup dimension by direct contextual $* p<.05 . * * p<.01$. value of the outgroup dimension in Experiment 1.

3.39, $S D=1.41)$ compared to participants in the ingroup condition $(M=4.67, S D=1.48), F(1,157)=31.31, p<$ $.001, \eta^{2}=.17$. However, no main effect of contextual emphasis (Hypothesis 1b) or interaction effect was found.

\section{Social Identity Protection}

We examined social identity protection by assessing the personal value that participants attached to both dimensions. Participants across conditions attached equal value to the outgroup dimension and did not protect social identity by devaluing this dimension. However, supporting Hypothesis 1a, the only reliable effect on personal value attached to the ingroup dimension was a main effect of group context, $F(1,164)=5.66$, $p=.018$, $\eta^{2}=.03$; that is, when anticipating an interaction with men, women attached more value to their ingroup dimension $(M=6.69, S D=1.03)$ than when anticipating an interaction with other women $(M=6.23, S D=1.42)$. Contrary to Hypothesis 1b, however, contextual emphasis on the ingroup dimension did not alleviate social identity protection.

We performed mediation analyses (Baron \& Kenny, 1986) to test whether the relationship between group context and the value that participants attached to the ingroup dimension was mediated by the value they expected other participants to attach to the outgroup dimension (Hypothesis 2a, see Figure 2). The direct relationship between group context and personal value attached to the ingroup dimension $(B=.47, S E=.19, p=$ .016 , semipartial $\left.r^{2}=.03\right)$ became unreliable $(B=.12$, $S E=.19, p=.54$, semipartial $r^{2}=.00$, Sobel test $=3.69, p<$ .001) when controlling for direct contextual value of the outgroup dimension. The relationship between personal value attached to the ingroup dimension and direct contextual value of the outgroup dimension remained highly significant $(B=.33, S E=.07, p<.001$, semipartial $\left.r^{2}=.13\right)$. Thus, consistent with Hypothesis 2, participants protected social identity in outgroup contexts by attaching higher value to the ingroup dimension because they expected other participants in that context to attach high value to the outgroup dimension.

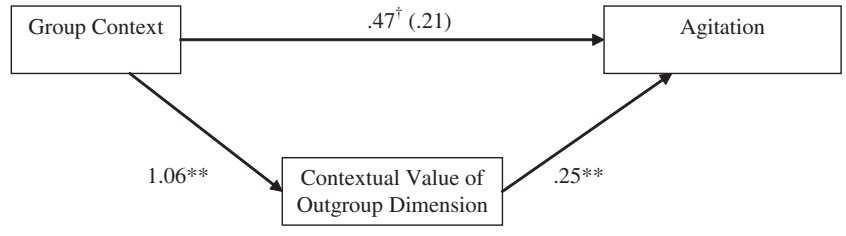

Figure 3 Mediation of the effect of group context on agitation by direct contextual value of the outgroup dimension in Experiment 1.

$\dagger p<.07 . * * p<.01$.

Emotions Indicating Focus on

Success Versus Failure

Supporting Hypothesis 1a, participants in the outgroup condition tended to report feeling more agitated when thinking about the performance feedback $(M=$ $4.45, S D=1.52$ ) than did participants in the ingroup condition $(M=3.98, S D=1.81), F(1,164)=3.41, p=.07, \eta^{2}=$ .02 , indicating a higher focus on failure. Other effects were unreliable. We performed mediation analyses to examine whether agitation was higher in the outgroup context because participants expected other participants in this context to value the outgroup dimension highly (see Figure 3). Indeed, the regression weight of group context $\left(B=.47, S E=.26, p=.07\right.$, semipartial $r^{2}=$ $.02)$ became unreliable $(B=.21, S E=.27, p=.44$, semipartial $r^{2}=.003$, Sobel test $=2.36, p=.02$ ) after direct contextual value of the outgroup dimension $(B=.25, S E=$ $.09, p<.01$, semipartial $\left.r^{2}=.04\right)$ was included in the regression equation. Thus, in accordance with Hypothesis 2 , participants were more agitated in outgroup contexts than in ingroup contexts because in these contexts they expected the outgroup dimension to be highly valued by other participants. ${ }^{1}$

In contrast to Hypothesis $1 \mathrm{~b}$, contextual emphasis on the ingroup or the outgroup dimension did not affect emotions indicating a focus on success.

\section{DISCUSSION}

This experiment showed that whether stigmatized group members functioned in ingroup or outgroup contexts influenced their attitude toward performance situations involving the outgroup dimension, their social identity protection, and their affective reactions to failure. Women reported a less negative attitude toward performing on the outgroup dimension when anticipating an interaction with other women than when anticipating an interaction with men. As expected, whereas in ingroup contexts, others in that context were perceived to attach more value to the ingroup dimension, in an outgroup context, others were perceived to attach more 
value to the outgroup dimension. Of importance, mediation analysis showed that women protected social identity by increasing the value that they attached to the ingroup dimension and felt more agitated (pointing to a higher focus on failure) because in an outgroup context others were perceived to value the outgroup dimension highly. The study thus clearly outlines why it is that outgroup contexts are threatening.

The strong effect of outgroup contexts on identity protection and affective reactions to failure could not be alleviated by contextual emphasis on the ingroup dimension as manipulated in this study. When participants in an outgroup context were expecting others with whom they would be interacting to value the outgroup dimension highly, the more distant contextual emphasis on the ingroup dimension by future employers did not influence their social identity protection and affective reactions. Because the value that others within the context attached to the outgroup dimension proved to be an important cause of social identity protection and emotions typical of a focus on failure, in Experiment 2, we manipulate this variable directly. Experiment 2 examines whether the strong effects of outgroup contexts can be alleviated by orthogonally manipulating group context and direct contextual value of the ingroup and/or the outgroup dimension. Moreover, by measuring emotional reactions to failure (i.e., agitation), Experiment 1 assessed a rather indirect indicator of focus on success versus failure. Experiment 2 improved the indicators of focus on success versus failure by also examining actual task behavior following failure on an outgroup dimension.

\section{EXPERIMENT 2}

In addition to group context, in Experiment 2, we manipulated the direct contextual value of the ingroup and/or the outgroup dimension by inducing participants to believe that other participants present valued particular dimensions (ingroup dimension/outgroup dimension/both dimensions). We hypothesized that the negative effects of an outgroup context on well-being and social identity protection could be alleviated by offering information implying a direct contextual emphasis (i.e., from others present in that context) on the ingroup dimension. In Experiment 2, we extended measures of well-being by assessing self-esteem on the outgroup dimension. Moreover, instead of focusing only on affective reactions to failure (Experiment 1), we examined affective reactions (relaxation/agitation and cheerfulness/dejection) to an anticipated achievement situation involving the outgroup dimension. Finally, we included a behavioral indicator of focus on success versus failure by examining participants' performance strategy while working on the outgroup dimension. This be- havioral indicator is an eight-item test based on Shah, Higgins, and Friedman (1998). In this test, participants are asked to complete items relevant to the outgroup dimension that are indicated in either green or red. Completing green items correctly results in gaining a point (focus on success), and completing red items correctly results in not losing a point (focus on nonfailure). By allowing participants to spend as much or as little time as they want on each item, and by recording on which type of item participants persist longest, it is possible to identify whether participants are working more at increasing success or at avoiding failure. Moreover, we also interpreted the number of correct and incorrect responses on this task. Research on the effects of regulatory focus on task performance (Crowe \& Higgins, 1997; Förster, Higgins, \& Bianco, 2003) shows that whereas individuals with a prevention focus (a focus on loss vs. nonloss) vigilantly try to avoid providing incorrect answers, individuals with a promotion focus eagerly strive to increase success by even providing answers that are possibly incorrect. Thus, we expected that compared to participants who focus on nonfailure, participants who focus on success would give more inaccurate answers, especially on the green items that were framed as serving the goal of achieving success. Similarly, we examined the number of correct answers given on the red items that were framed as leading to nonfailure. Relative differences between conditions in the number of correct answers given on the red items framed as serving the goal of avoiding failure thus indicate a difference in the degree to which individuals invest effort to prevent failure.

\section{Hypotheses}

As in Experiment 1, we hypothesized that compared to ingroup contexts, outgroup contexts lead to more social identity threat and induce a focus on failure (Hypothesis 1a). This would be evident from a more negative attitude toward a performance situation concerning the outgroup dimension, more social identity protection, and lower self-esteem on the outgroup dimension. Moreover, we expected participants in outgroup contexts to report more emotions indicating a focus on failure (i.e., agitation), to invest more time toward avoiding failure on the outgroup dimension, to provide more correct answers on items framed in terms of avoiding failure, and fewer incorrect answers on items framed in terms of approaching success. In addition, we expected that direct contextual emphasis on the ingroup dimension, compared to direct contextual emphasis on the outgroup dimension, would alleviate some of these negative effects of outgroup contexts (Hypothesis 1b). This would be evident from a more positive attitude toward a performance situation involving the outgroup dimension, less social identity protection, and higher self- 
esteem on the outgroup dimension. Moreover, we expected a direct contextual emphasis on the ingroup dimension to result in more reported emotions indicating a focus on success (i.e., cheerfulness) when thinking about performing on the outgroup dimension, more time invested toward achieving success on the outgroup dimension, fewer correct answers on items framed in terms of avoiding failure, and more incorrect answers on items framed in terms of approaching success.

\section{METHOD}

\section{Participants}

Participants were 182 female students of Leiden University in the Netherlands. Following a conservative suspicion check, 29 participants were excluded because they questioned the authenticity of other participants' statements or whether the oral examination would take place. $^{2}$ The remaining 153 participants had a mean age of 21 years $(S D=2.80)$.

\section{Procedure}

The procedure was similar to Experiment 1 with respect to the cover story, the creative integration and inferential flexibility tests, and personal and group performance feedback. Again, participants were told that an oral examination would take place; however, in contrast to Experiment 1, they were told that their performance on both the ingroup and the outgroup dimension would be assessed. Next, participants were asked two openended questions and were told that their answers would serve to introduce them to the other participants. First, they were asked how they felt about participating in this study, and then they were asked how important they thought the two performance dimensions were.

Manipulation of group context. Participants were informed that the oral examination would take place in the presence of either three women or three men. This manipulation was checked with seven items similar to those in Experiment $1(\alpha=.90)$.

Manipulation of direct contextual emphasis. Next, participants were introduced to the other three participants with whom they would take the oral examination by showing them their (preprogrammed) answers to the open-ended questions. In addition to general comments regarding the experiment (e.g., "I think this experiment is interesting"), these statements either emphasized the ingroup dimension, the outgroup dimension, or both dimensions (e.g., "I want to perform well on the test of creative integration/inferential flexibility/both tests because my brother had to take the [se] test[s] when he applied for a job"). We checked this manipulation by asking participants to indicate on a 9-point scale which of the two abilities they expected to be most valued by the other three participants (scored such that $1=$ outgroup dimension valued most, 5 = both dimensions valued equally, and $9=$ ingroup dimension valued most). After assessing self-report measures (see below), participants were given $15 \mathrm{~min}$ to practice the test of the outgroup dimension, after which the behavioral measure of focus on success versus nonfailure was administered. Finally, participants were checked for suspicion about the manipulations and were debriefed, thanked, and paid for their participation.

\section{Measures}

All self-report measures were assessed on 9-point scales. We measured attitude toward the oral examination with one item (i.e., "I am looking forward to performing the oral examination of creative integration"). Personal value attached to the ingroup and the outgroup dimension was examined with the same three questions for each dimension as in Experiment $1\left(\alpha_{\text {ingroup }}\right.$ dimension $\left.=.77, \alpha_{\text {outgroup dimension }}=.74\right)$. To measure emotions related to focus on success versus nonsuccess, we asked how cheerful (cheerful, confident, and capable, $\alpha=.86$ ) and dejected (disappointed and discouraged, $r=.62$ ) participants felt when thinking about the oral examination. Similarly, to examine emotions related to focus on failure versus nonfailure, we asked how agitated (tense, nervous, and anxious, $\alpha=.89$ ) and relaxed (quiet, relaxed, $r=.80$ ) participants felt. We measured self-esteem on the outgroup dimension with six items from the Rosenberg (1979) Self-Esteem Scale that we adjusted to measure state self-esteem on the outgroup dimension (e.g., "At this moment I am satisfied with my creative integration ability," $\alpha=.88$ ). The behavioral measure of focus on success versus nonfailure consisted of an eightitem test of the outgroup dimension. Participants were asked to view four green and four red items. Giving a correct answer on the green items would result in earning one point. Failing a red item would result in losing one point. There was no time limit on the items and participants could skip items without answering. Every item also included a reminder of the consequences of a correct or incorrect answer $(1 / 0$ for green items vs. $0 /-1$ for red items). We measured the time that participants worked on the items and whether items completed were answered correctly or incorrectly.

\section{RESULTS}

\section{Manipulation Checks}

As intended, participants in the ingroup condition perceived the group in which the oral examination was to be administered to consist of more women $(M=3.95$, $S D=.60)$ than did participants in the outgroup condi- 
tion $(M=6.96, S D=.61), F(1,147)=920.82, p<.001, \eta^{2}=$ .86 . No other effects were found.

As predicted, perceived direct contextual value of the ingroup and outgroup dimension was affected by direct contextual emphasis, $F(2,147)=69.98, p<.001, \eta^{2}=.49$. When both dimensions were emphasized, participants expected others to value both dimensions equally $(M=$ $4.65, S D=1.00$ ), but when one dimension was emphasized, participants expected others to value that dimension more than the other dimension $\left(M_{\text {outgroup dimension }}=\right.$ $\left.3.06, S D=1.99 ; M_{\text {ingroup dimension }}=6.61, S D=1.59\right)$. Moreover, replicating results of Experiment 1, group context affected perceived contextual value, $F(1,147)=16.85$, $p<.001, \eta^{2}=.10$. Whereas participants in the ingroup context expected other participants to favor the ingroup dimension $(M=5.29, S D=1.98)$, participants in the outgroup context expected other participants to favor the outgroup dimension $(M=4.30, S D=2.13)$. The interaction was unreliable. Thus, although the manipulation of direct contextual emphasis was successful, group context also influenced which dimension participants expected others to value.

\section{Attitude Toward the Oral Examination}

of the Outgroup Dimension

Consistent with Hypothesis 1a, whereas participants in the ingroup condition reported a neutral attitude toward the oral examination $(M=4.99, S D=2.13)$, participants in the outgroup condition reported a negative attitude toward this achievement situation $(M=4.26, S D=$ 1.96), $F(1,147)=4.91, p=.03, \eta^{2}=.03$. Other effects were nonsignificant. Thus, direct contextual emphasis could not alleviate this negative attitude, $F(2,147)=1.33, p=$ .27 .

\section{Self-Esteem on the Outgroup Dimension}

Consistent with Hypothesis 1a, self-esteem on the outgroup dimension was higher in the ingroup condition $(M=4.57, S D=1.63)$ than in the outgroup condition $(M=4.02, S D=1.56), F(1,147)=4.63, p=.03, \eta^{2}=.03$. Furthermore, consistent with Hypothesis 1b, self-esteem on the outgroup dimension was higher when the ingroup dimension $(M=5.12, S D=1.68)$ or both dimensions $(M=4.63, S D=1.49)$ were emphasized by other participants, compared to when only the outgroup dimension was emphasized $(M=3.90, S D=1.52), F(2,147)=$ $5.05, p<.01, \mathrm{~h}^{2}=.06$. No interaction was found. Thus, outgroup contexts affected well-being, reducing selfesteem on the outgroup dimension. However, direct contextual emphasis alleviated this effect, resulting in higher self-esteem on the outgroup dimension when both dimensions or the ingroup dimension was emphasized by others.

\section{Social Identity Protection}

Consistent with Hypothesis $1 \mathrm{~b}$, a context that emphasized the importance of both dimensions prevented participants from devaluing the outgroup dimension. Participants attached highest value to the outgroup dimension when others emphasized both dimensions $(M=$ $6.96, S D=1.12$ ) compared to when others emphasized only the ingroup dimension $(M=6.32, S D=1.29)$ or the outgroup dimension $(M=6.65, S D=1.14), F(2,147)=$ $3.81, p=.02, \eta^{2}=.05$. No other effects were found.

The personal value participants attached to the ingroup dimension was only significantly affected by the two-way interaction, $F(2,147)=2.94, p=.056, \eta^{2}=.03$. Women increased the value they attached to the ingroup dimension when they perceived high direct contextual value of the outgroup dimension (when participants were in an outgroup context or when others in the context emphasized the importance of the outgroup dimension). Thus, similar to Experiment 1, regardless of which dimension was emphasized, all three outgroup contexts led women to attach high value to the ingroup dimension (Hypothesis $1 \mathrm{a}, M=6.80, S D=1.15, F<1$ ). In the ingroup contexts, personal value attached to the ingroup dimension increased when others emphasized the outgroup dimension $(M=6.97, S D=1.21)$ or both dimensions $(M=7.30, S D=1.18)$, but not when other women emphasized the ingroup dimension $(M=6.49$, $S D=1.11), F(2,77)=3.27, p=.04, \eta^{2}=.08$.

\section{Focus on Success Versus Failure}

To control for differences in item difficulty in the behavioral measure of focus on success versus failure, we calculated $z$ scores of time spent on each individual item. We formed measures of focus on success and failure by adding the standardized times on red and green items separately. When analyzing the number of correct answers on the red items and the number of incorrect answers on the green items, we entered two covariates, namely, the number of either correct or incorrect answers on the earlier creative integration test and the total time spent on either the red or the green items. This procedure corrected for preexisting individual differences in ability and separated this measure from time spent on the items.

Do outgroup contexts lead to a focus on failure (Hypothesis 1a)? Although relaxation was equal across conditions $(M=4.48, S D=1.64)$, consistent with Experiment 1, participants felt more agitated, pointing to more focus on failure, in the outgroup contexts $(M=5.37, S D=1.71)$ than in the ingroup contexts $(M=4.77, S D=1.70), F(1$, $147)=4.51, p=.04, \eta^{2}=.03$. No other effects were found. Moreover, group context affected whether participants invested time toward approaching success (green items) 
or avoiding failure (red items). Specifically, an ANOVA on a difference score (subtracting standardized time spent on the green items from standardized time spent on the red items) showed only a significant main effect of group context: Whereas participants in the ingroup contexts spent more time on the items that could increase success than on the items that could diminish failure $(M=-.48, S D=2.35)$, participants in the outgroup contexts spent more time on the items that would diminish failure than on the items that would increase success $(M=.53, S D=2.63), F(1,147)=6.28, p=.01, \eta^{2}=.04$. Group context did not affect the number of incorrect or correct answers participants provided on the red and green items $(F<1)$. Thus, outgroup contexts led participants to feel more agitated and to invest more time completing items on which they risked losing a point by not answering correctly, indicating a focus on failure. Ingroup contexts, on the other hand, led participants to feel less agitated and to invest more time in completing items by which they could gain a point when they would answer correctly, indicating a focus on success.

Does contextual emphasis on the ingroup dimension lead to a focus on success (Hypothesis 1b)? Consistent with Hypothesis $1 \mathrm{~b}$, cheerfulness was significantly affected by contextual emphasis only: Participants felt more cheerful thinking about the oral examination when others valued the ingroup dimension $(M=4.83, S D=1.28)$ or both dimensions $(M=4.78, S D=1.39)$ than when the outgroup dimension was emphasized $(M=4.15, S D=1.46), F(2$, $147)=3.57, p=.03, \eta^{2}=.05$. Not predicted, but consistent with the group context effect on attitude toward the oral examination, dejection was affected by group context only: Participants reported higher dejection in outgroup contexts $(M=4.38, S D=1.75)$ than in ingroup contexts $(M=3.83, S D=1.57), F(1,147)=4.09, p=.04, \eta^{2}=.03$. Although direct contextual emphasis did not affect how much time participants spent on items leading to success or nonfailure $(F<1)$, direct contextual emphasis did affect how participants performed within that time. Consistent with decreased cheerfulness, the number of correct answers on the red items (avoiding failure) was influenced by direct contextual emphasis only, $F(2,145)$ $=3.49, p=.03, \eta^{2}=.05$. Specifically, when the outgroup dimension was emphasized, participants performed more accurately on items that were framed as avoiding failure $(M=2.76, S E=0.17)$ compared to when the ingroup dimension $(M=2.15, S E=.17)$ or both dimensions $(M=$ 2.33, $S E=.16$ ) were emphasized. This indicates that a context that emphasized the outgroup dimension exclusively led participants to focus their performance on nonfailure rather than on success. In addition, the number of incorrect answers given on items that were framed as leading to success was affected by an interaction only, $F(2,145)=4.50, p=.01, \eta^{2}=.06$. Specifically, whereas par- ticipants in the ingroup context provided on average one incorrect answer on the green items independent of direct contextual emphasis $(M=1.00, S E=.10), F(2,75)=$ $1.95, p=.15, \eta^{2}=.05$, participants in the outgroup context gave more incorrect answers when the ingroup dimension $(M=1.40, S E=.17)$ or both dimensions were emphasized $(M=1.19, S E=.17)$ than when the outgroup dimension was emphasized $(M=.77, S E=.18), F(2,68)=$ $3.72, p=.03, \eta^{2}=.10$. Thus, whereas participants in an ingroup context were equally focused on success regardless of contextual emphasis, among participants in the outgroup context, a direct emphasis on the ingroup dimension or both dimensions led to a higher focus on success than did emphasis on the outgroup dimension.

In conclusion, the results for Hypothesis $1 \mathrm{~b}$ showed that when others in the context emphasized the ingroup dimension or both dimensions, participants felt more cheerful and were less concerned with accuracy. These findings indicate a focus on success when others emphasized the ingroup dimension or both dimensions and a focus on nonfailure when others emphasized the outgroup dimension.

\section{DISCUSSION}

Replicating and extending the results of Experiment 1, Experiment 2 confirmed the adverse effects of outgroup contexts on members of stigmatized groups. Among women, outgroup contexts resulted in more negative attitude toward a performance situation involving the outgroup dimension and lower self-esteem on this dimension. Moreover, women showed more evidence of social identity protection in the form of attaching high value to the ingroup dimension in outgroup contexts. Finally, whereas ingroup contexts induced women to spend energy toward increasing success, outgroup contexts induced women to spend time toward avoiding failure and made them feel more agitated, indicating that they were focused on failure.

However, Experiment 2 also showed that a direct contextual emphasis on the ingroup dimension alleviated some of these negative effects. Although contextual emphasis could not change women's negative attitude toward the upcoming performance situation in the outgroup context, when others in the context valued both dimensions women had more confidence in their ability on the outgroup dimension and valued the outgroup dimension more. Because personal value attached to the outgroup dimension is a predictor of motivation to perform on this dimension, this last finding is important. The current study also showed that emphasizing the ingroup dimension led women to focus on success in achievement situations: When the ingroup dimension was emphasized, participants not only felt more cheerful but also were less preoccupied with avoiding failure. 
Thus, when the ingroup dimension was emphasized, participants were less motivated to come up with accurate answers on items that could lower their chances of failure. Moreover, for participants in the outgroup context, emphasizing the ingroup dimension increased a focus on success, as was indicated by the higher number of attempts, even if incorrect, on the items that were framed as leading to success. Thus, emphasizing the ingroup dimension in outgroup contexts tempted participants to focus more on the possibility that an answer was correct (leading to success) than on the possibility that the answer was incorrect (leading to failure).

Of importance, most of the effects of direct emphasis on the ingroup dimension were main effects, indicating that when others within a context communicate that they value both the ingroup and the outgroup dimension, this potentially increases stigmatized group members' well-being and focus on success in ingroup as well as outgroup settings.

\section{GENERAL DISCUSSION}

In two experiments, we showed how contexts that are dominated by high-status group members affect members of stigmatized groups. Not only do stigmatized group members' well-being and social identity suffer from being confronted with members of the high-status outgroup but outgroup contexts also can induce a focus on failure affecting stigmatized group members' performance and persistence on status-defining dimensions. An important contribution of this research is that it sheds light on the psychological process underlying social identity threat in outgroup contexts. The results show that outgroup contexts increase the perception that the outgroup dimension is highly valued within that context. Because stigmatized group members expect to fail on this dimension, outgroup contexts become threatening environments in which stigmatized group members become focused on failure and protect their social identity by valuing ingroup dimensions. Of importance, we found that some of these negative effects of outgroup contexts can be alleviated by contextually emphasizing an ingroup dimension. When others within the context communicate that they value both the statusdefining outgroup dimension and an alternative dimension of importance to the stigmatized group, stigmatized group members have more confidence in their ability on the outgroup dimension, value this outgroup dimension more, and seek success instead of avoiding failure. Although clearly outgroup dimensions are not all that matter to members of low-status groups, these dimensions often are the dimensions that determine status in society and are thus key in raising the status of stigmatized groups.
The process described in this article is related to processes described in stereotype threat theory (Steele, Spencer, \& Aronson, 2002) and self-affirmation theory (Steele, 1988) but also differs from these concepts. Stereotype threat denotes concerns about fulfilling negative personal or group stereotypes and appears to be driven by cognitive and ideomotor processes that lower the performance of stigmatized individuals due to distraction. The issue of concern in this article, however, is the self-protective withdrawal of performance motivation on status-defining dimensions following explicit group devaluation on these dimensions. This process is more similar to disidentification processes (which can be an outcome of stereotype threat). Our research shows how stigmatized group members who are confronted with explicit devaluation of their ingroup become focused on possible success on outgroup dimensions in a context that offers social identity protection. Moreover, the process we describe differs from self-affirmation (Steele, 1988 ) in that it allows stigmatized group members to selfcategorize on the group level instead of directing them to their personal identity as a source of self-value. This is important because it influences intergroup behavior: Individuals who self-categorize as a group member will more likely show progroup behavior such as collective action aimed at increasing group status, whereas a focus on one's personal identity will most likely lead to individual mobility, which can actually reinforce intergroup status differences (Ellemers, 2001; Ellemers, Van Den Heuvel, De Gilder, Maass, \& Bonvini, 2004; Wright, 2001).

The results of the present research point to a potentially negative effect of placing stigmatized group members, such as ethnic minorities, in situations in which they are surrounded by high-status group members. Although previous research has noted important benefits of integration on the performance of minority students (Simmons, Brown, Bush, \& Blyth, 1978), the current research highlights possible negative effects of outgroup settings. Our research speaks to debates concerning how ethnic minorities can become integrated into multicultural societies. For example, various European governments are introducing policies that prevent ethnic minorities from wearing symbols of religious identity, such as the Islamic veil, in an effort to prevent differentiation by ethnicity and increase the status of these groups. The research presented here suggests, however, that ethnic minorities can perceive such measures as expressing low regard for dimensions that define their ingroup (such as their ethnic background or religion), leading them to emphasize the value of these dimensions and to become focused on avoiding failure instead of approaching success. The emphasis on dimensions that are typical of the higher status groups in society that is expressed by such measures could then actually cause more (instead of 
less) differentiation between groups and could discourage ethnic minorities who strive for higher status (Barreto \& Ellemers, in press).

On a more positive note, the research presented here suggests that outgroup contexts can become less threatening to low-status group members, enabling them to become more focused on success and to attach value to outgroup dimensions when ingroup dimensions are valued within these contexts. Thus, ethnic minority school children within integrated classes become focused on increasing success, can value school, and feel more confident in their ability when other children in the classroom express that they value both academic performance and dimensions that are characteristic of ethnic minorities (such as their cultural background or their religion). As such, this research again underlines the importance of intergroup respect and differentiation. Existing theoretical models, such as the mutual intergroup differentiation model (Hewstone \& Brown, 1986) and the ingroup projection model (Mummendey \& Wenzel, 1999), note that low-status group members need a distinctive subgroup identity and that characteristics of this identity need to be valued by other subgroups for them to feel part of a superordinate category (see also Hornsey \& Hogg, 2000; Huo \& Molina, in press). Similarly, Steele (2004) argues that minorities in integrated settings need a sense of "identity safety," a psychological state that arises in contexts in which individuals feel that their identity is valued, for them to feel comfortable enough to achieve their optimal potential. Our research indicates that by valuing and respecting their characteristic traits, stigmatized group members are able to remain identified with outgroup dimensions and will feel more confident performing on these dimensions.

Future research is necessary to identify the key characteristics of ingroup dimensions that help enhance stigmatized group members' social identity and elicit a focus on success. Questions remain as to whether these dimensions necessarily need to be performance dimensions (e.g., cognitive skills, interpersonal skills) that protect social identity through increased perceptions of efficacy. Moreover, would value expressed by outgroup members for another characteristic of the ingroup unrelated to performance (e.g., religion, cultural habits) also increase motivation on outgroup dimension because this communicates subgroup respect (Huo \& Molina, in press)? Another important extension would be to investigate whether social identity enhancement by valuing ingroup dimensions indeed increases behavior aimed at improving group status, whereas self-affirmation by valuing dimensions on which the individual excels elicits individual mobility strategies. We are currently pursuing these issues in further research.
The results of these two experiments suggest that to alleviate the negative effects of outgroup contexts, the contextual value of the ingroup dimension has to be expressed within that context (Experiment 2) and not by a source outside the context (Experiment 1). To achieve this, high-status group members must express value for dimensions that are characteristic of stigmatized groups. For instance, White children in White schools can come to attach more value to dimensions that are important to ethnic minority children (e.g., cultural background, religion) through diversity teaching programs that inform them about diversity between groups and emphasize the importance of multiculturalism and intergroup respect. Similarly, through contact programs and diversity training, employees with different cultural backgrounds can learn about each other and can come to mutually respect and value their differences. When high-status group members in intergroup contexts emphasize both the importance of dimensions that define their group's high status and dimensions on which stigmatized groups excel, intergroup settings can become challenging contexts in which stigmatized group members can overcome the barriers that their stigma poses and achieve their full potential.

\section{NOTES}

1. We also ruled out the alternative causal chain that agitation mediates the effect of context on perceived direct contextual value.

2. This number is higher than in Experiment 1 because prior to this experiment other researchers at Leiden University, using the same subject pool, performed experiments in which they manipulated an anticipated interaction with other participants. As a result, some participants indicated not believing that there would be an oral examination and had to be removed from the study.

\section{REFERENCES}

Baron, R. M., \& Kenny, D. A. (1986). The moderator-mediator variable distinction in social psychological research: Conceptual, strategic, and statistical considerations. Journal of Personality and Social Psychology, 51(6), 1173-1182.

Barreto, M., \& Ellemers, N. (in press). Multiple identities and the paradox of social inclusion. In F. Butera \& J. M. Levine (Eds.), Coping with minority status: Responses to exclusion and inclusion. New York: Cambridge University Press.

Crocker, J., \& Major, B. (1989). Social stigma and self-esteem: The self-protective properties of stigma. Psychological Review, 96(4), 608-630.

Crowe, E., \& Higgins, E. (1997). Regulatory focus and strategic inclinations: Promotion and prevention in decision-making. Organizational Behavior and Human Decision Processes, 69(2), 117-132.

Ellemers, N. (2001). Individual upward mobility and the perceived legitimacy of intergroup relations. In J. T. Jost \& B. Major (Eds.), The psychology of legitimacy: Emerging perspectives on ideology, justice, and intergroup relations (pp. 205-222). New York: Cambridge University Press.

Ellemers, N., Van Den Heuvel, H., De Gilder, D., Maass, A., \& Bonvini, A. (2004). The underrepresentation of women in science: Differential commitment or the queen bee syndrome? British Journal of Social Psychology, 43(3), 315-338. 
Elliot, A. J., \& Church, M. A. (1997). A hierarchical model of approach and avoidance achievement motivation. Journal of Personality and Social Psychology, 72(1), 218-232.

Förster, J., Higgins, E., \& Bianco, A. T. (2003). Speed/accuracy decisions in task performance: Built-in trade-off or separate strategic concerns? Organizational Behavior and Human Decision Processes, 90(1), 148-164.

Hewstone, M., \& Brown, R. (1986). Contact is not enough: An intergroup perspective on the "contact hypothesis." In R. Brown \& M. Hewstone (Eds.), Contact and conflict in intergroup encounters (pp. 1-44). Cambridge, MA: Basil Blackwell.

Higgins, E. T. (1997). Beyond pleasure and pain. American Psychologist, 52(12), 1280-1300.

Higgins, E. T., Shah, J., \& Friedman, R. (1997). Emotional responses to goal attainment: Strength of regulatory focus as moderator. Journal of Personality and Social Psychology, 72(3), 515-525.

Hornsey, M. J., \& Hogg, M. A. (2000). Assimilation and diversity: An integrative model of subgroup relations. Personality and Social Psychology Review, 4(2), 143-156.

Huo, Y., \& Molina, L. (in press). Is pluralism a viable model for diversity? The benefits and limits of subgroup respect. Group Processes and Intergroup Relations.

Inzlicht, M., \& Ben-Zeev, T. (2000). A threatening intellectual environment: Why females are susceptible to experiencing problemsolving deficits in the presence of males. Psychological Science, $11(5), 365-371$.

McFarlin, D. B., \& Blascovich, J. (1984). On the remote associates test (rat) as an alternative to illusory performance feedback: A methodological note. Basic and Applied Social Psychology, 5(3), 223-229.

McGuire, W. J., \& Padawer Singer, A. (1976). Trait salience in the spontaneous self-concept. Journal of Personality and Social Psychology, 33(6), 743-754.

Mummendey, A., \& Wenzel, M. (1999). Social discrimination and tolerance in intergroup relations: Reactions to intergroup difference. Personality and Social Psychology Review, 3(2), 158-174.

Rosenberg, M. (1979). Conceiving the self. New York: Basic Books.

Schmader, T., \& Major, B. (1999). The impact of ingroup vs. outgroup performance on personal values. Journal of Experimental Social Psychology, 35(1), 47-67.

Seibt, B., \& Förster, J. (2004). Stereotype threat and performance: How self-stereotypes influence processing by inducing regulatory foci. Journal of Personality and Social Psychology, 87(1), 38-56.
Sekaquaptewa, D., \& Thompson, M. (2003). Solo status, stereotype threat, and performance expectancies: Their effects on women's performance. Journal of Experimental Social Psychology, 39(1), 68-74.

Shah, J., Higgins, E. T., \& Friedman, R. S. (1998). Performance incentives and means: How regulatory focus influences goal attainment. Journal of Personality and Social Psychology, 74(2), 285-293.

Simmons, R. G., Brown, L., Bush, D. M., \& Blyth, D. A. (1978). Selfesteem and achievement of Black and White adolescents. Social Problems, 26(1), 86-96.

Spears, R., Doosje, B., \& Ellemers, N. (1999). Commitment and the context of social perception. In N. Ellemers \& R. Spears (Eds.), Social identity: Context, commitment, content (pp. 59-83). Oxford, UK: Blackwell Science.

Steele, C. M. (1988). The psychology of self-affirmation: Sustaining the integrity of the self. In L. Berkowitz (Ed.), Advances in experimental social psychology (Vol. 21, pp. 261-302). San Diego, CA: Academic Press.

Steele, C. M. (2004). A theory of diverse settings: How identity contingencies shape interactions, performance, and comfort in diverse schools and workplaces. Paper presented at the Society for the Psychological Study of Social Issues, Washington, DC.

Steele, C. M., Spencer, S. J., \& Aronson, J. (2002). Contending with group image: The psychology of stereotype and social identity threat. In M. P. Zanna (Ed.), Advances in experimental social psychology (Vol. 34, pp. 379-440). San Diego, CA: Academic Press.

Swan, S., \& Wyer, R. S., Jr. (1997). Gender stereotypes and social identity: How being in the minority affects judgment of self and others. Personality and Social Psychology Bulletin, 23(12), 1265-1276.

Tajfel, H., \& Turner, J. C. (1986). The social identity theory of intergroup behavior. In S. Worchel \& W. G. Austin (Eds.), The psychology of intergroup relations (pp. 7-24). Chicago: Nelson-Hall.

Turner, J. C., Hogg, M. A., Oakes, P. J., Reicher, S. D., \& Wetherell, M. S. (1987). Rediscovering the social group: A self-categorization theory. New York: Basil Blackwell.

Wright, S. C. (2001). Strategic collective action: Social psychology and social change. In R. Brown \& S. Gaertner (Eds.), Intergroup processes (pp. 409-431). Oxford, UK: Blackwell.

Received March 15, 2005

Revision accepted July 29, 2005 